\title{
Radio-frequency attenuation beneath Siple Dome, West Antarctica, from wide-angle and profiling radar observations
}

\author{
Dale P. Winebrenner, ${ }^{1}$ Benjamin E. SMith,${ }^{2}$ Ginny A. CATAniA, ${ }^{2}$ Howard B. CONWAY, ${ }^{2}$ \\ Gharles F. RAYMOND ${ }^{2}$ \\ ${ }^{1}$ Applied Physics Laboratory, University of Washington, Box 355640, 1013 N.E. 40th Street, Seattle, WA 98105-6698, U.S.A. \\ E-mail:dpw@apl.washington.edu \\ ${ }^{2}$ Department of Earth and Space Sciences, Box 351310, University of Washington, Seattle, WA 98195-1310, U.S.A.
}

\begin{abstract}
Knowledge of the spatial distribution of bed lubrication regimes, i.e. frozen vs wet conditions, is crucial for understanding ice-sheet flow. Radar sounding can probe differing reflectivities between wet and frozen beds, but is limited by uncertainty in attenuation within the ice of bed echoes. Here we present two methods to estimate attenuation: (1) wideangle radar sounding, in which source and receiver locations are varied so as to vary propagation path length, and thus echo amplitude; and (2) profiling, in which similar variations are obtained by sounding through varying ice thicknesses (assuming constant bed reflectivity). Siple Dome, West Antarctica, provides unusually favorable circumstances for application of these methods: the bed beneath Siple Dome is flat and uniform in its radar reflectivity, while ice thickness varies by several hundred meters. Wide-angle data $4 \mathrm{~km}$ from the summit yield an estimate for characteristic attenuation length of $124 \mathrm{~m} \mathrm{(35} \mathrm{dB} \mathrm{km}{ }^{-1}$ loss $)$, whereas profiling yields an estimate of $168 \mathrm{~m}$. The difference between estimates is modest compared to the range of attenuation lengths reported in the literature. It may nonetheless prove informative by bounding effects of two ice properties to which the methods respond differently: (1) wide-angle sounding sampled relatively warm (lossy) ice beneath the summit, whereas the profiling method sampled relatively cold ice beneath the flanks as well; and (2) strain-induced crystal orientation fabrics and resulting dielectric anisotropy in the ice would vary from summit to flank, and may influence wide-angle sounding more strongly than profiling.
\end{abstract}

\section{INTRODUGTION}

Radar echo sounding (RES) at megahertz frequencies responds directly to basal water because of the strong dielectric contrast between liquid water and most other geological materials. Thus RES has been used to probe ice-sheet bed conditions with significant success. For example, studies by Bentley and others (1998) and Gades and others (2000) used airborne and ground-based RES (respectively) to compare streng ths of basal reflections beneath Siple Coast ice streams and inter-ice-stream ridges. Interpretation of the comparisons shows wetness beneath both dormant and active ice streams, a lack of wetness beneath ridges, and coincidence of transitions between bed conditions with independently known shear margins; these are significant results in the investigation of fast-flow dynamics. Both studies, however, depended on circumstances in which the variations of interest remained visible despite neglect of possible spatial variations in ice absorption.

A much more common situation is that in which uncertainty about such variations renders apparent differences in bed reflection inconclusive (Bogorodsky and others, 1985; Shabtaie and others, 1987). RES probing of the bed in most locations relies on models for ice absorption that depend on temperature, impurity content and grain-size (Corr and others, 1993; Wolff and others, 1997). In practice, however, inputs and functional dependencies in the models are often highly uncertain, and model results remain largely untested against direct observation (Bogorodsky and others, 1985; Shabtaie and others, 1987). This situation may be especially problematic in precisely one of the most interesting situations, where variations in geothermal flux may produce simultaneous variations in ice temperature and basal conditions (Blankenship and others, 1993; Fahnestock and others, 2001).

Direct measurement of electromagnetic absorption in ice sheets would thus be glaciologically valuable. Perhaps the most elementary basis for such methods is observation of the change in radar signal intensity with varying length of a propagation path through the ice. Here we present and demonstrate two methods based on path-length variation, using ground-based RES data from Siple Dome, West Antarctica (which, we will show, is particularly well suited for this initial work). Attenuation estimates from the two methods differ little relative to the expected range of attenuations in ice sheets, but the difference may nonetheless be informative, because it may serve to bound possible effects of temperature regimes and dielectric anisotropy which are probed differently by the two methods.

\section{BED ECHO CHARAGTERISTICS AT SIPLE DOME}

Both of our methods use the ice-sheet bed as a reflector so that various propagation path lengths can be observed at 


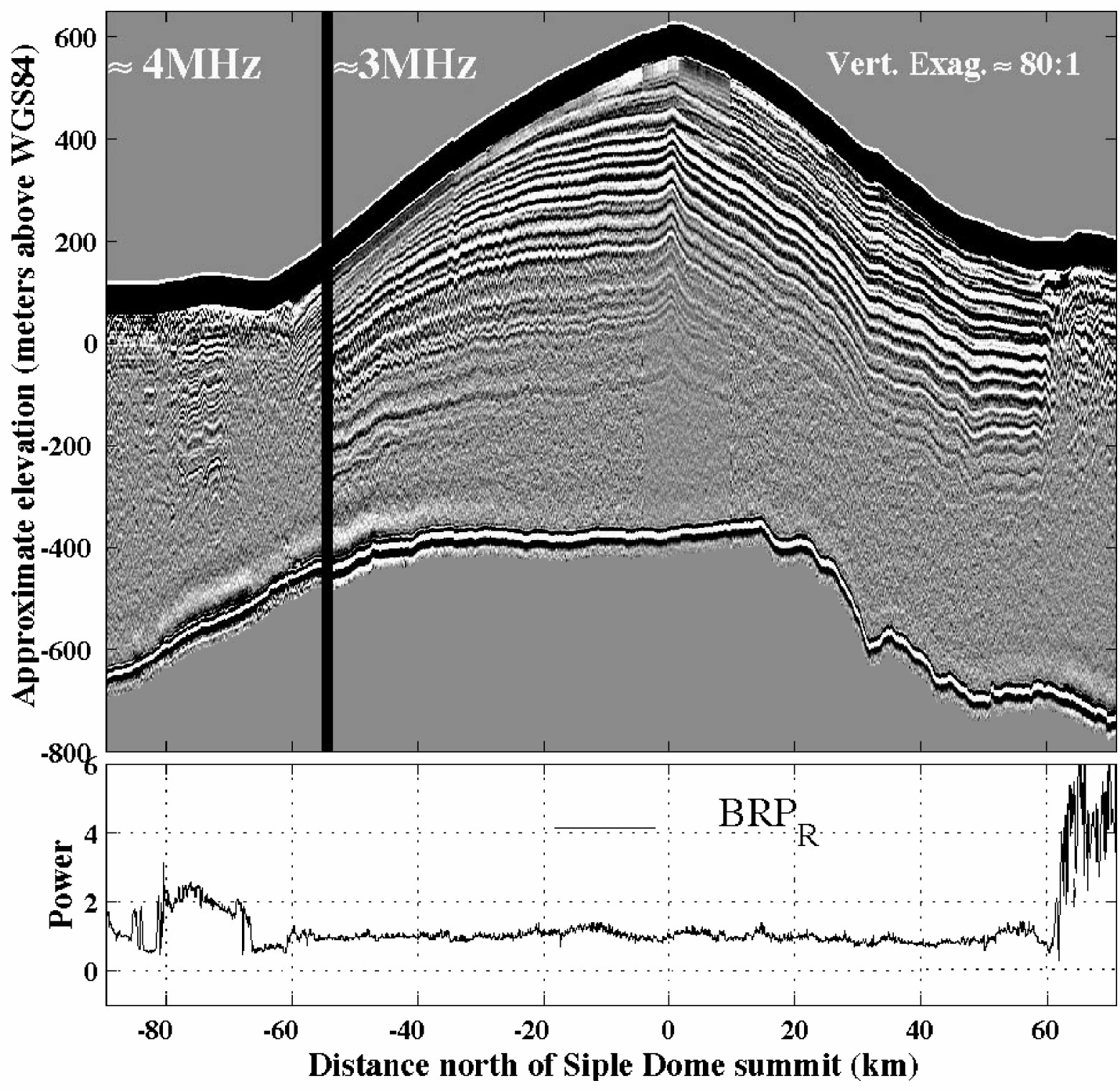

Fig. 1. Data from a conventional radar sounding transit across Siple Dome, together with estimates of the relative power of bed reflection after an empirical correction for ice thickness (as discussed in the text and explained in detail by Gades and others (2000)).

the (relatively accessible) ice-sheet surface. Thus, properties of the reflector must, implicitly or explicitly, be taken into account. Here we discuss observations of those properties for the special case pertaining to our measurements.

The RES data for this study were acquired with a lowfrequency $(3-5 \mathrm{MHz})$ monopulse radar (Jacobel and others, 1996, 2000; Gades, 1998) during the course of several field seasons on Siple Dome. Siple Dome provides an unusually favorable location for initial development and application of our methods because most of its bed is unusually flat and homogeneous in apparent radar reflectivity (at least at the low frequencies we use). Figure 1 shows an RES profile (upper panel) and derived data (lower panel) from a transect across Siple Dome, including the summit. In the lower panel we have plotted, as a function of position, the apparent bed-reflected power, $\mathrm{BRP}_{\mathrm{R}}$, which was defined by Gades and others (2000) as an estimate of bed-reflected power after empirical correction for varying thickness of overlying ice. In this work, we utilize only the portion of transect on which data of $3 \mathrm{MHz}$ center frequency were acquired within roughly $10 \mathrm{~km}$ north and $40 \mathrm{~km}$ south of the summit; for this portion, the apparent bed-reflected power, and thus presumably the bed reflectivity, varies by at most $10 \%$.
New observations suggest that $5 \mathrm{MHz}$ bed reflections beneath Siple Dome summit are not only homogeneous in magnitude, but also highly coherent. During the 2001/02 field season, we acquired stacks of roughly 2000 echoes (using the radar in the standard, nadir-looking configuration) while stationary at each of 201 points spaced $1 \mathrm{~m}$ apart, along a line within a few hundred meters of the summit (essentially at the point marked $0 \mathrm{~km}$ in Figure 1). Stacking reduces environmental and system noise in the echoes and thus yields estimates of the coherent reflection as a function of travel time beneath the radar. For display here, we have also band-pass filtered the echoes (with band edges of 3 and $8 \mathrm{MHz}$ ) to further reduce noise. Figure 2 shows an "A-scope" plot of the portions of the stacked, filtered echoes that contain the bed return. It is apparent that not only the amplitudes, but also the phases and details of the bed-reflected waveforms, are nearly invariant for all echoes along the line. Provisionally using the square of the maximum signal amplitude (Morse, 1997) as a measure of echo intensity, $I$, we compute a standard measure of signal coherence, the "scintillation index", defined by $m=$ variance $(I) /[\operatorname{mean}(I)]^{2}$. (A scintillation index of 0 indicates complete coherence, whereas random, uncorrelated values of $I$ result in $m=1$.) For the stacked filtered data, 


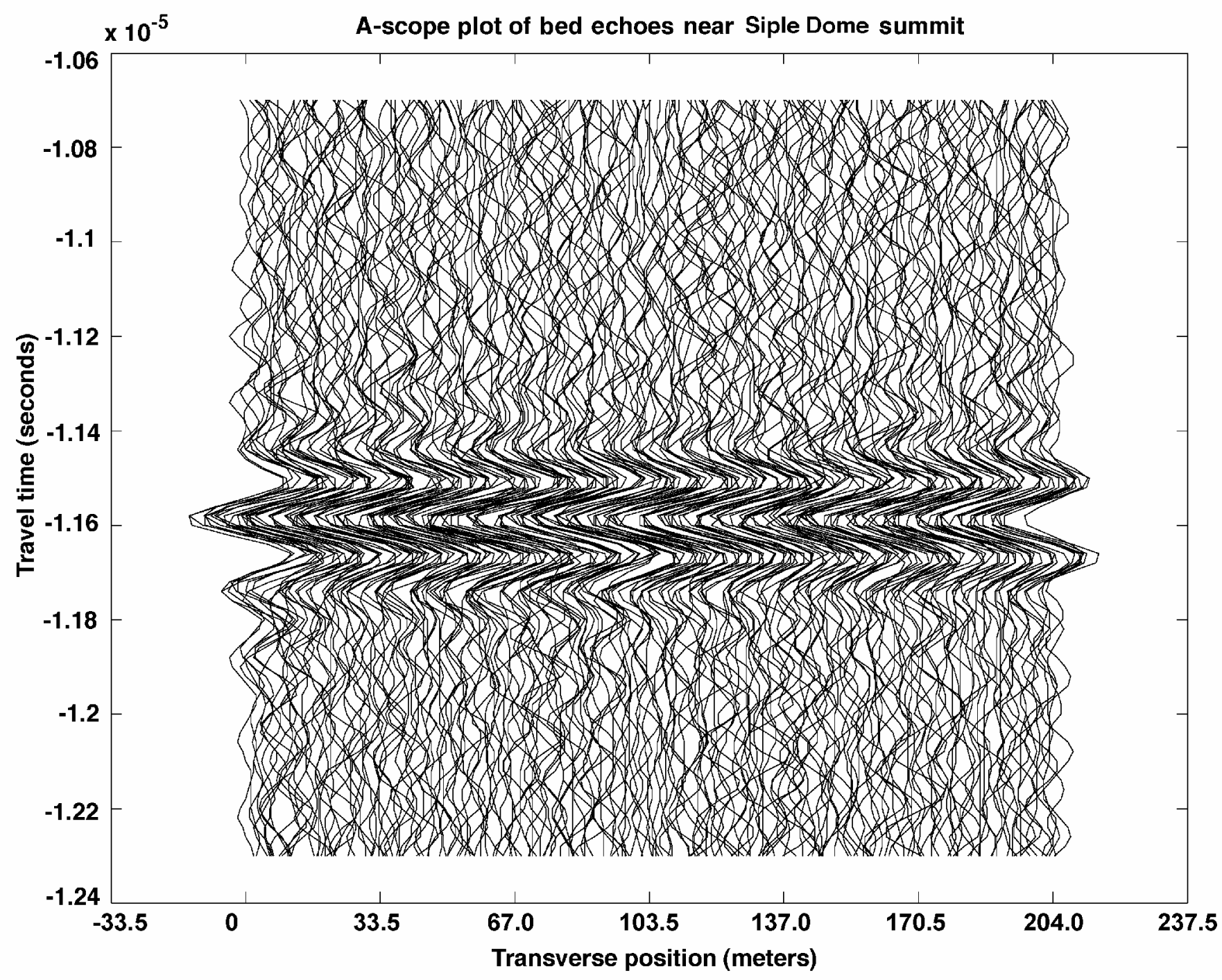

Fig. 2. Successive stacks of roughly 2000 bed echoes, spaced $1 \mathrm{~m}$ apart along a line $200 \mathrm{~m}$ long, near Siple Dome summit, displayed in the so-called "A-scope" format.

$m=0.107$; even stacked but otherwise unfiltered data yield $m=0.114$. Both results quantify the high degree of coherence across transverse distances on the order of hundreds of meters.

Comparison of Figure 2 with figures 3 and 4 of Schultz and others (1987), which are analogous plots of observations at $50 \mathrm{MHz}$ onWhillans Ice Stream (formerly Ice Stream B), shows that our situation does not hold for all locations and radar frequencies. However, at Siple Dome and at 3-5 MHz frequency, these observations suggest that bed reflection can be approximated by simple Fresnel reflection from a sharp interface at the bed.

\section{WIDE-ANGLE SOUNDING FOR ATTENUATION}

Figure 3 shows schematically the particular wide-angle sounding geometry we have thus far employed, in which source and receiver locations are arranged in pairs centered on a common midpoint (CMP). Reflection or scattering at the bed completes the variable-length path through the ice between transmitter and receiver, and we observe the variation in echo intensity with varying path length. GMP sounding maintains a common specular point on the bed for all pairs (in the absence of relative slope between surface and bed), and the reflecting bed area varies only minimally. Although CMP radar sounding has been used to estimate average wave speed and thickness in ice sheets, based on the variation of echo arrival time with separation (see, e.g., Jezek and others, 1978, and references therein), we know of no previous study in which the variation of echo intensity has been used to probe an ice sheet.

The particular CMP data used here were acquired in 1994 by Jacobel and Gades (Jacobel and others, 1996, 2000) $4 \mathrm{~km}$ southeast of the summit of Siple Dome (ice thickness $996 \mathrm{~m}$, roughly at the location of the $-4 \mathrm{~km}$ point in Figure 1). The transmitting and receiving antennas were both resistively loaded dipoles resonant at $3 \mathrm{MHz}$, placed parallel (i.e. broadside) on the snow at 11 separations ranging from 100 to $1100 \mathrm{~m}$.

In its simplest form, our estimation method can be derived from the conventional radar equation for ice-sheet sounding (Bogorodsky and others, 1985). In this initial analysis, we neglect the (small) effects of refraction and focusing in the firn (Bogorodsky and others, 1985), and we assume that the power supplied to the transmitter, and the receiver response to voltage across its terminals, are identical for all separations. In this case (see also Fig. 3),

$$
I(\theta)=\frac{G(\theta) P_{\mathrm{t}}}{4 \pi} \frac{1}{(2 R)^{2}} \mathcal{R}(\theta) \exp \left(-2 \kappa_{H} R\right),
$$

where $I(\theta)$ is the received echo intensity (defined as in the previous section) for the source/receiver separation corres- 


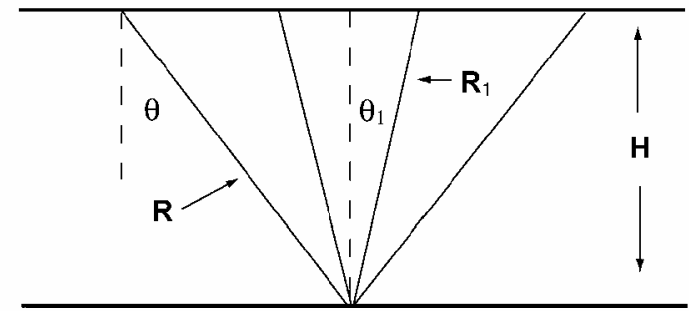

Surface

Fig. 3. Common-midpoint sounding geometry, for two separations. Ice thickness is $H$. In general, range to the bed from (either) transmitter or receiver is $R$, and the propagation path makes an angle $\theta$ with the vertical (we neglect nearsurface refraction). Quantities associated with the minimum transmitter/receiver separation are denoted by subscript 1 .

ponding to specular angle $\theta$ and range to the bed $R, P_{\mathrm{t}}$ is the power input to the source antenna, $G(\theta)$ is the effective directional antenna gain in the ice accounting for both transmission and reception, $\mathcal{R}(\theta)$ is power reflectivity of the bed, and $\kappa_{H}$ is the depth average of the (generally depth-dependent) power attenuation per unit length in the ice, $\kappa(z)$ over the depth range $0-H$, the ice thickness:

$$
\kappa_{H}=\frac{1}{H} \int_{0}^{H} \kappa(z) \mathrm{d} z .
$$

The depth-averaged attenuation coefficient appears in Equation (1) because the increment of power loss at each depth is multiplicative, i.e. additive in the argument of the exponential function. Because we neglect refraction in this analysis, the same depth-averaged attenuation coefficient applies for each source/receiver separation.

Although the power attenuation coefficient is the theoretically natural quantity, it is less intuitive than the common measure of absorption in units of $\mathrm{dB} \mathrm{km}^{-1}, N_{\mathrm{a}}$, or the characteristic (e-folding) length of absorption, $L_{\mathrm{a}}$ in units of meters. The depth-averaged versions of these quantities are related to $\kappa_{H}$ in units of $\mathrm{m}^{-1}$ according to:

$$
\begin{aligned}
N_{\mathrm{a}} & =1000\left(10 \log _{10} e\right) \kappa_{H} \approx 4343 \kappa_{H}\left(\mathrm{dBkm}^{-1}\right), \\
L_{\mathrm{a}} & =\frac{1}{\kappa_{H}}(\mathrm{~m}) .
\end{aligned}
$$

If attenuation is interpreted in terms of an effective conductivity, then a depth-averaged version of the effective conductivity can be naturally defined by a relationship analogous to that between the attenuation coefficient $\kappa(z)$ at depth $z$ and the effective conductivity at that depth: $\sigma\left(\Omega^{-1} \mathrm{~m}^{-1}\right)=$ $\kappa_{H} \sqrt{\epsilon_{\mathrm{r}}} / Z_{0}$, where $\epsilon_{\mathrm{r}}$ is the real part of the relative permittivity of the ice and $Z_{0}$ is the impedance of free space.

Our method relies not on absolute intensities, but rather on intensities normalized to that intensity observed at the shortest separation (corresponding to quantities in Figure 3 with subscript 1$)$ :

$$
\begin{aligned}
\frac{I(\theta)}{I\left(\theta_{1}\right)}= & \frac{G(\theta)}{G\left(\theta_{1}\right)} \frac{\cos ^{2}(\theta)}{\cos ^{2}\left(\theta_{1}\right)} \frac{\mathcal{R}(\theta)}{\mathcal{R}\left(\theta_{1}\right)} \\
& \cdot \exp \left[-2 \kappa_{H} H\left(\frac{1}{\cos (\theta)}-\frac{1}{\cos \left(\theta_{1}\right)}\right)\right],
\end{aligned}
$$

where we have written ranges to the bed, $R$ and $R_{1}$, in terms of the ice-sheet thickness and the cosines of the propagation angles. Notice that the intensity ratio depends not on the individual values of bed reflectivities at the two angles, but rather only on their ratio. To use observations of the intensity

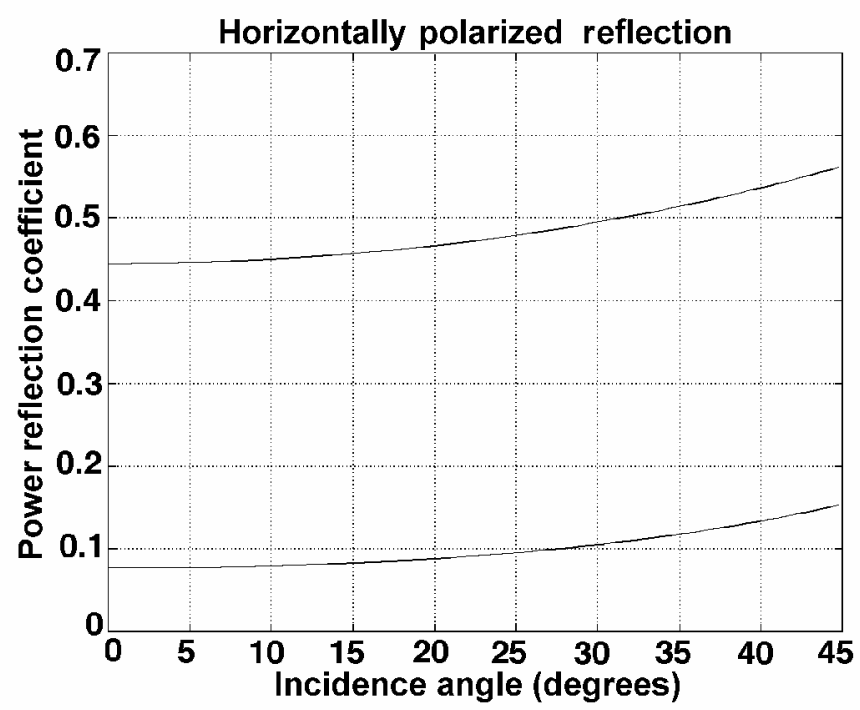

Fig. 4. Angular dependences of Fresnel power reflectivity for plane interfaces separating materials with relative permittivities characteristic of ice (3.2) from (upper curve) a wet ice-sheet bed (80) and (lower curve) rock (10). Note the large difference in level but near-congruence of the angular-dependence curves.

ratio to infer $\kappa_{H}$, we must model the reflectivity ratio, as well as the angular dependence of the normalized (combined transmission/reception) gain. We assume that $H$ and the cosines of $\theta$ and $\theta_{1}$ are known (as they could, for example, easily be derived from timing data from the same CMP experiment that yields the intensity ratio data (Jezek and others, 1978)).

Based on the observations shown in the previous section, we propose perhaps the simplest model for the Siple Dome bed reflectivity ratio at $3-5 \mathrm{MHz}$, namely a coherent, Fresnel reflection from a sharp interface at the bed. While this model is likely to be appropriate only for exceptionally smooth beds (which may occur only rarely) and long radar wavelength, it is evidently consistent with our observations at Siple Dome. Figure 4 shows plots of the Fresnel power reflectivity of an ice/bed interface as a function of angle, for horizontal polarization (determined by the antenna configuration), assuming a relative permittivity for the ice of 3.2. The two curves correspond to differing relative permittivities of the bed: 10, corresponding to rock, for the lower curve, and 80, corresponding to liquid water, for the upper curve. Notice that although the magnitude of reflection differs greatly between the bed models, the "shapes" of the angular dependences are nearly identical. More precisely, the reflectivity ratio in Equation (4), for any $\theta_{1}$ close to zero, is very nearly independent of the dielectric contrast at the bed for the full range of physically plausible contrasts. Thus we can invert Equation (4) for $\kappa_{H}$, independent of whether the bed is wet or frozen, by using a simple functional fit (in practice, a second-order polynomial in $\cos (\theta)$ ) to the Fresnel reflectivity ratio.

For this initial work, we also assume that the gain pattern, $G$, for the resistively loaded dipoles on the snow surface is independent of angle. This assumption is certainly an oversimplification because of (generally complicated) near-field coupling between transmit and receive antennas in near-contact with the snow surface, particularly at the shorter separations in our dataset (West and Demarest, 1987; Morse, 1997). However, this assumption can be refined 

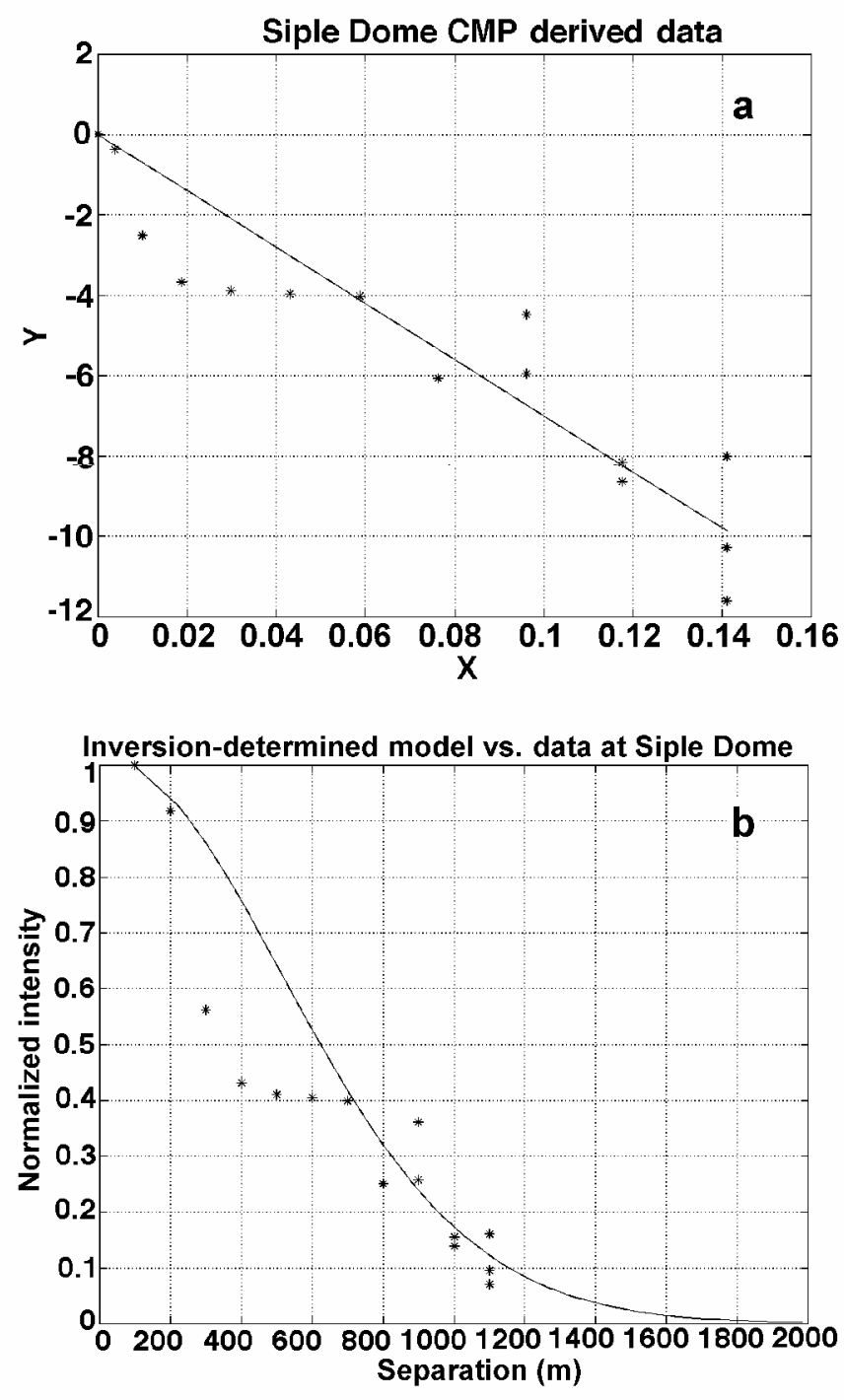

Fig. 5. ( a) Plot of (X,Y) pairs derived from Siple Dome CMP observations and our assumptions (denoted by ${ }^{*}$ ), together with a least-squares linear fit. (b) Plot of observed ratios of echo intensities vs separation (denoted by $*_{s}$ ), together with the prediction according to Equation (4) and our estimated absorption length and assumptions.

at the next stage of investigation and, based on the results below, is unlikely to greatly alter our results.

We proceed by rearranging Equation (4) to relate a synthetic dependent variable composed of intensity ratio observations and the other known or modeled ratios to a synthetic independent variable derived from the geometry of the CMP observation pairs.

$$
\frac{I(\theta)}{I\left(\theta_{1}\right)} \frac{G\left(\theta_{1}\right)}{G(\theta)} \frac{\cos ^{2}\left(\theta_{1}\right)}{\cos ^{2}(\theta)} \frac{\mathcal{R}\left(\theta_{1}\right)}{\mathcal{R}(\theta)}=\exp \left(-2 \kappa_{H} H X\right),
$$

where $X$ is defined by

$$
X=\frac{1}{\cos (\theta)}-\frac{1}{\cos \left(\theta_{1}\right)} .
$$

This equation can be stably inverted for $\kappa_{H}$ by transforming it to

$$
\begin{aligned}
Y & =10 \log _{10}\left[\frac{I(\theta)}{I\left(\theta_{1}\right)} \frac{G\left(\theta_{1}\right)}{G(\theta)} \frac{\cos ^{2}\left(\theta_{1}\right)}{\cos ^{2}(\theta)} \frac{\mathcal{R}\left(\theta_{1}\right)}{\mathcal{R}(\theta)}\right] \\
& =\left(-20 \log _{10} e\right) \kappa_{H} H X,
\end{aligned}
$$

which is the equation of a straight line constrained (by the normalization) to pass through the origin. We fit a line to

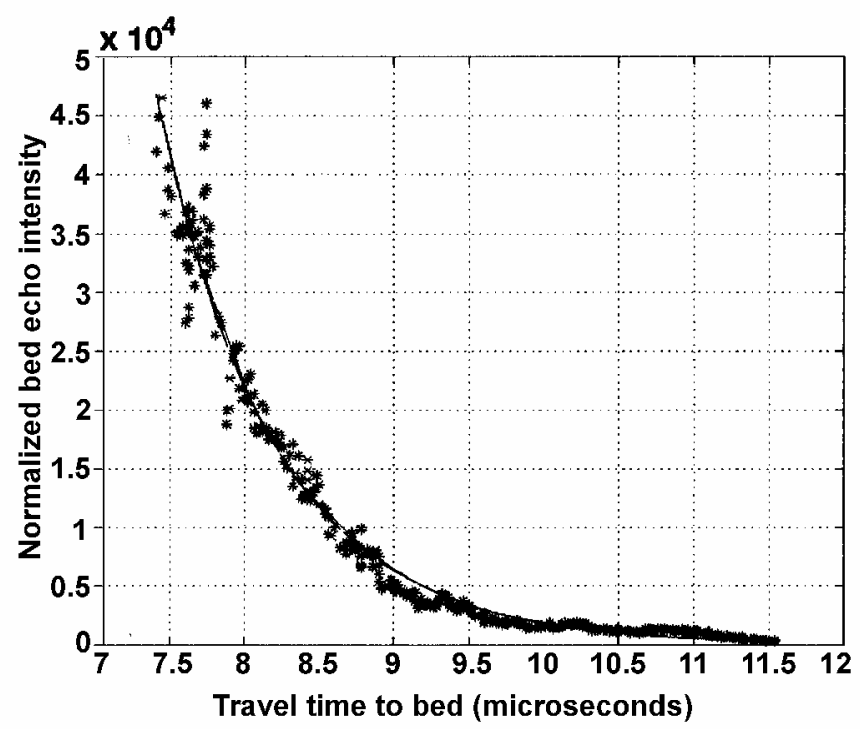

Fig. 6. Apparent reflected bed intensity vs travel time to the bed, or effectively distance. Fitting a model for the ratio of intensities at two travel times (thus cancelling system gains, etc.), we obtain an estimate of $168 \mathrm{~m}$ for the characteristic absorption length.

observed $(X, Y)$ pairs in the least-squares sense. The stability of the estimated slope in the presence of noise is considerably increased by the constraint that the fitted line must pass through the origin. In this way we are able to estimate the effective absorption length scale in the ice using an uncalibrated radar over a bed of uncertain absolute reflectivity. In this simple version of our method, we have neglected, in addition to the relatively simple details noted above, any effects of anisotropic dielectric properties in the ice (Doake, 1981; Fujita and others, 1999).

Figure 5 a shows a plot of $(X, Y)$ pairs for the CMP data described above. Repeated symbols at some values of $X$ indicate repeated observations at the corresponding separation, without movement of antennas or other equipment; these repeated observations serve to indicate observational uncertainty due to environmental and system noise. Data points deviate from the fitted line by amounts similar to differences among repeated observations, suggesting that our approximations are at least roughly correct. The characteristic absorption length estimated from the slope of the fitted line is $124 \mathrm{~m}$ (corresponding to $N_{\mathrm{a}}=35 \mathrm{~dB} \mathrm{~km}^{-1}$, or a depthaveraged effective conductivity of $\sigma=3.81 \times 10^{-5} \Omega^{-1} \mathrm{~m}^{-1}$ ).

Figure $5 \mathrm{~b}$ shows the predicted relationship between echo intensity ratios and separation based on our estimate of absorption length. Note that the intensity ratios are purely observations and involve no assumptions or modeling. Thus our inversion yields a self-consistent result.

\section{PROFILE-BASED ESTIMATION OF ATTENUA- TION}

Because ice thickness on Siple Dome varies significantly over a homogeneous bed (Gades and others, 2000), we can estimate $\kappa_{H}$ in a nearly independent way by analysis of the observed relationship between bed echo intensity and ice thickness in conventional radar profile data (Catania and others, 2002).

Figure 6 shows the observed relationship between received bed-echo intensity (defined as in section 2, in unnor- 
malized units of voltage squared) and travel time to the bed (which is converted to ice thickness assuming a wavespeed of $170 \mathrm{~m} \mu \mathrm{s}^{-1}$ ) for the radar profile shown in Figure 1. (These data are the basis on which Gades and others (2000) computed their measure of apparent bed-reflected power, $\mathrm{BRP}_{\mathrm{R}}$. We now assume that $\mathrm{BRP}_{\mathrm{R}}$ is in fact constant across the full range of data used here, and analyze the variation of received power to estimate $\kappa_{H}$.) If the absorption length scale is also assumed to be constant across the Dome, data from different points on the profile differ only in the path length of propagation and associated geometrical spreading. Then the ratio of intensities $I$ and $I_{0}$ from differing profile points for which travel times to the bed are $t$ and $t_{0}$, respectively, is given by:

$$
\frac{I}{I_{0}}=\frac{t_{0}^{2}}{t^{2}} \exp \left[-2 \kappa_{H} c\left(t-t_{0}\right)\right]
$$

where $c$ is the wave speed in the ice. Notice that antenna gain patterns cancel entirely in this case, and thus uncertainties in those patterns are of no consequence.

To estimate $\kappa_{H}$ we rearrange Equation (8) into the form $I=\left(C / t^{2}\right) \exp \left(-2 \kappa_{H} c t\right)$ and use a grid-search algorithm with the unnormalized data in Figure 6 to find values of $\kappa_{H}$ and the constant $C$ that minimize the rms difference between this model and our data. The resulting estimate of the characteristic absorption length is $168 \mathrm{~m}$ (corresponding to $N_{\mathrm{a}}=26 \mathrm{~dB} \mathrm{~km}^{-1}$, or a depth-averaged effective conductivity of $\sigma=2.81 \times 10^{-5} \Omega^{-1} \mathrm{~m}^{-1}$ ).

\section{DISGUSSION}

The difference of $44 \mathrm{~m}$ between our two estimates is roughly an order of magnitude smaller than the range of absorption lengths reported for polar ice sheets (Bogorodsky and others, 1985; Shabtaie and others, 1987). We view this level of agreement as encouraging, in view of the facts that none of the observations used here were intended for the estimation of attenuation and that our initial CMP analysis neglects some corrections and any effects of dielectric anisotropy in the ice.

Anisotropy could affect results of our two methods quite differently: Our profiling observations are all made at essentially nadir incidence, i.e. using propagation directions that differ little from the principal direction of radio-frequency anisotropy expected from strains beneath an ice dome (Fujita and others, 1999; Thorsteinsson and others, 1999). Although the strength of strain-induced anisotropy may vary across Siple Dome, the orientation of profiling observations appears likely to minimize any effect of anisotropy. Our CMP observations at the summit, however, employ propagation paths off nadir at a number of angles ranging out to roughly $45^{\circ}$ (Hargreaves, 1977, 1978; Doake, 1981). Conversion between polarization modes for such propagation paths could significantly alter our echo intensities. The level of agreement we observe, however, suggests that, at least at Siple Dome, the magnitude of any such effects is at most about $30 \%$. Moreover, our two methods sampled ice of possibly significantly differing temperatures: The depthvarying attenuation coefficient at depth $z, \kappa(z)$, is proportional to the loss tangent, $\tan \delta$, at that depth. The loss tangent varies strongly with temperature $T$ near the melting temperature, $T_{\mathrm{m}}$, (according to a relationship of the form $\tan \delta=A \exp \left[-B\left(T^{-1}-T_{\mathrm{m}}^{-1}\right)\right]$, where $A$ and $B$ are constants). The basal temperature beneath Siple Dome summit is approximately $271 \mathrm{~K}$, and temperature in the ice sheet decreases almost linearly with height to $248 \mathrm{~K}$ at the icesheet surface (H. Engelhardt, http://skua.gps.caltech.edu). Thus the depth-averaged attenuation coefficient, $\kappa_{H}$, is controlled largely by the warmer, near-basal temperature. Ice on the flanks of the Dome is thinner, and therefore likely to be colder and less attenuating near its bed, than ice near the summit where the CMP observations were made. Our observation of a lower attenuation in the profiling observations is qualitatively consistent with this effect, and because this mechanism must almost certainly account for part of our discrepancy, it further limits the possible effects of dielectric anisotropy.

Quantification of these final observations is clearly required, and can be expected to yield insight into both dielectric anisotropy in the particular flow environment of Siple Dome and the temperature dependence of attenuation. The next step in our analysis is therefore inclusion of corrections for antenna effects and analysis of differing results from the two methods in this light.

\section{AGKNOWLEDGEMENTS}

We thank R.W. Jacobel for providing CMP observations from Siple Dome and for valuable discussions, and G. R. Bentley for additional helpful discussion. This work was supported by the NASA Earth Science Enterprise, grant NAG5-10225.

\section{REFERENCES}

Bentley, C. R., N. Lord and C. Liu. 1998. Radar reflections reveal a wet bed beneath stagnant Ice Stream $\mathrm{C}$ and a frozen bed beneath ridge $\mathrm{BC}$, West Antarctica. F. Glaciol., 44(146), 149-156.

Blankenship, D. D., R. E. Bell, S. M. Hodge, J. M. Brozena, J. C. Behrendt and C. A. Finn. 1993. Active volcanism beneath the West Antarctic ice sheet and implications for ice-sheet stability. Nature, 361 (6412), 526-529.

Bogorodsky, V.V., C. R. Bentley and P. E. Gudmandsen. 1985. Radioglaciology. Dordrecht, etc., D. Reidel Publishing Co.

Catania, G. A., H. B. Conway, A. M. Gades, C. F. Raymond and H. Engelhardt. 2003. Bed-reflectivity beneath inactive ice streams in West Antarctica. Ann. Glaciol., 36, 287-291.

Corr, H., J. C. Moore and K.W. Nicholls. 1993. Radar absorption due to impurities in Antarctic ice. Geophys. Res. Lett., 20(11), 1071-1074.

Doake, C. S. M. 1981. Polarization of radio waves in ice sheets. Geophys. F. R. Astron. Soc., 64(2), 539-558.

Fahnestock, M., W. Abdalati, I. Joughin, J. Brozena and P. Gogineni. 2001. High geothermal heat flow, basal melt, and the origin of rapid ice flow in central Greenland. Science, 294(5550), 2338-2342.

Fujita, S. and6 others. 1999. Nature of radio-echo layering in the Antarctic ice sheet detected by a two-frequency experiment. 7. Geophys. Res., 104(B6), 13,013-13,024.

Gades, A. M. 1998. Spatial and temporal variations of basal conditions beneath glaciers and ice sheets inferred from radio echo soundings. (Ph.D. thesis, University of Washington.)

Gades, A. M., C. F. Raymond, H. Conway and R.W. Jacobel. 2000. Bed properties of Siple Dome and adjacent ice streams, West Antarctica, inferred from radio-echo sounding measurements. F. Glaciol., 46(152), 88-94.

Hargreaves, N. D. 1977. The polarization of radio signals in the radio echo sounding of ice sheets. F. Phys. D, 10 $(9), 1285-1304$.

Hargreaves, N. D. 1978. The radio-frequency birefringence of polar ice. $\mathcal{F}$ Glaciol., 21 (85), 301-313.

Jacobel, R.W., T. A. Scambos, C. F. Raymond and A. M. Gades. 1996 Changes in the configuration of ice stream flow from the West Antarctic ice sheet. 7. Geophys. Res., 101(B3), 5499-5504.

Jacobel, R.W., T. A. Scambos, N. A. Nereson and C. F. Raymond. 2000. Changes in the margin of Ice Stream C, Antarctica. 7. Glaciol., 46(152), 102-110.

Jezek, K. G., J.W. Clough, C. R. Bentley and S. Shabtaie. 1978. Dielectric permittivity of glacier ice measured in situ by radar wide-angle reflection. F. Glaciol., 21 (85), 315-329.

Morse, D. L. 1997. Glacier geophysics at Taylor Dome, Antarctica. (Ph.D. thesis, University of Washington. 
Schultz, D. G., L. A. Powell and C. R. Bentley. 1987. A digital radar system for echo studies on ice sheets. Ann. Glaciol., 9, 206-210.

Shabtaie, S., I. M. Whillans and C. R. Bentley. 1987. The morphology of Ice Streams A, B, and C, West Antarctica, and their environs. 7. Geophys. Res., 92(B9), 8865-8883.

Thorsteinsson, T., E. D. Waddington, K. C. Taylor, R. B. Alley and D. D. Blankenship. 1999. Strain-rate enhancement at Dye 3, Greenland. $\mathcal{F}$. Glaciol., 45(150), 338-345.
West, J. C. and K. R. Demarest. 1987. The radiation characteristics of an arbitrary antenna positioned on a polar ice sheet. Geophysics, 52(12), 1689-1696. Wolff, E. W., W. D. Miners, J. C. Moore and J. G. Paren. 1997. Factors controlling the electrical conductivity of ice from the polar regions - a summary. F. Phys. Chem., 101(32), 6090-6094. 